\title{
The effect of disease-associated HRPT2 mutations on splicing
}

\author{
Michael A Hahn, Julie McDonnell and Deborah J Marsh \\ Hormones and Cancer Group, Kolling Institute of Medical Research, Royal North Shore Hospital, University of Sydney, E25, St Leonards, \\ New South Wales 2065, Australia \\ (Correspondence should be addressed to D J Marsh; Email: dmarsh@med.usyd.edu.au)
}

\begin{abstract}
Mutations in the tumour suppressor HRPT2 occur in patients with parathyroid carcinoma, kidney tumours and Hyperparathyroidism-Jaw Tumour syndrome. Disruption of exonic splicing through mutation of donor/acceptor splice sites or exonic splice enhancer (ESE) sites leads to loss of function of a number of major tumour suppressors including BRCA1, $A P C$ and MLH1. Given that the effect of HRPT2 mutations on splicing has not been widely studied, we used an in vitro splicing assay to determine whether 17 HRPT2 mutations located in hot-spot and other exons predicted to disrupt ESE consensus sites led to aberrant splicing. Using two independent web-based prediction programs, the majority of these mutations were predicted to disrupt ESE consensus sites; however, aberrant splicing of HRPT2 transcripts was not
\end{abstract}

observed. Canonical donor or acceptor splice site mutations were also investigated using this splicing assay and transcripts assessed from tumour tissue. Splice site mutations were shown to lead to either exon skipping or retention of intronic sequences through the use of cryptic splice sites comprised of non-classical splicing signals. Aberrant splicing caused by disruption of ESE sites does not appear to have a major role in HRPT2-associated disease; however, premature truncation of parafibromin as the result of canonical donor or acceptor splice site mutations is associated with pathogenicity. Functional splicing assays must be undertaken in order to confirm web-based software predictions of the modification of putative ESE sites by disease-associated mutations.

Journal of Endocrinology (2009) 201, 387-396

\section{Introduction}

HRPT2, also known as CDC73 or C1orf28, is a ubiquitously expressed tumour suppressor that contains 17 exons that encode the 531 amino acid protein parafibromin (Carpten et al. 2002). Linkage analysis was used to map this gene to 1q25-q31; however, recent mapping data available through Ensembl suggests a more discreet location for HRPT2 at 1q31.2. Parafibromin is a member of the PAF1 complex that is associated with RNA polymerase II-related transcriptional initiation and elongation (Rozenblatt-Rozen et al. 2005, Yart et al. 2005). To date, over 60 mutations have been reported, both in the germline of patients with HyperparathyroidismJaw Tumour (HPT-JT) syndrome (Carpten et al. 2002, Marsh et al. 2007) and Familial Isolated Hyperparathyroidism (FIHP; Simonds et al. 2004), as well as somatic mutations in sporadic parathyroid carcinoma (Howell et al. 2003, Shattuck et al. 2003) and kidney tumours (Zhao et al. 2007). Approximately $80 \%$ of mutations occur in exons 1, 2 or 7 (Marsh et al. 2007). Loss of the wild-type HRPT2 allele, as well as 'second-hit' mutations have been reported (Howell et al. 2003, Bradley et al. 2006, Kelly et al. 2006, Cetani et al. 2007). The vast majority of HRPT2 mutations are predicted to prematurely truncate parafibromin; however, seven missense mutations have also been reported (reviewed in Marsh et al. 2007).
Accurate demarcation of intron/exon boundaries is required for correct pre-mRNA splicing and is achieved by critical sequences including $5^{\prime}$ and $3^{\prime}$ splice sites as well as exonic splice enhancer (ESE) sequences. ESE motifs are distinct but degenerate six to eight nucleotide sequences that bind the conserved family of splicing factors known as serine/argininerich proteins (SR proteins) including SF2/ASF, SC35, SRp40 and SRp55. SR proteins bind to ESE consensus motifs through their RNA-binding domain and recruit spliceosomal components that function to define exons.

Recently, some mutations in the coding regions of genes thought to function by premature introduction of a stop codon or alteration of single amino acids have been shown to affect premRNA splicing by disruption of ESE sequences leading to exon skipping (Cartegni et al. 2002, Blencowe 2006). This has been reported for a number of tumour suppressor genes including BRCA1 (Mazoyer et al. 1998), BRCA2 (Fackenthal et al. 2002), APC (Montera et al. 2001, Aretz et al. 2004), MLH1 (Nystrom-Lahti et al. 1999) and NF1 (Colapietro et al. 2003).

We have used the web-based resources ESEfinder (Cartegni et al. 2003) and Rescue-ESE (Fairbrother et al. 2002) to predict whether 17 reported missense, non-sense and small insertion or deletion HRPT2 mutations alter ESE sites. Using an in vitro splicing assay, we have assessed whether these mutations, as well as reported mutations at canonical donor/ acceptor splice sites, cause aberrant splicing. 


\section{Materials and Methods}

\section{Prediction of ESE site disruption}

The web-based prediction softwares ESEfinder (http://rulai. cshl.edu/cgi-bin/tools/ESE3/esefinder.cgi?process $=$ home) and Rescue-ESE (http://genes.mit.edu/burgelab/rescueese/) were used to determine whether 17 mutations in HRPT2 hot-spot exons 2 and 7, as well as 4 and 5, previously identified in patients with HPT-JT or parathyroid carcinoma were likely to disrupt ESE sites.

\section{Hybrid minigene construction}

Three hybrid minigene cassettes were constructed to investigate putative splicing variants induced by mutations in HRPT2 exons 2, 4/5 and 7 respectively pTBNde-HR2, pTBNde-HR 4/5 and pTBNde-HR7 (Fig. 1). All sequences were compared with NCBI Genbank Accession number AL390863. Given the small size of IVS4 (83 nucleotides), exons 4 and 5 were able to be studied in a single construct. Wild-type HRPT2 consisting of the $3^{\prime} 279$ nucleotides of intron 1, exon $2(106 \mathrm{bp})$ and the $5^{\prime} 246$ nucleotides of intron 2 was PCR amplified from genomic DNA (Promega) using the primers 5'-TAATCATATGTGGTAAAGCCCAGAGCCTAAT- $3^{\prime}$ and $5^{\prime}$-TGCTCATATGACAGCAAGACCCCCTCATC- $3^{\prime}$. Wild-type HRPT2 consisting of the 3' 399 nucleotides of intron 3, exon 4 (63 bp), intron 4 (83 bp), exon 5 (53 bp) and the $5^{\prime} 184$ nucleotides of intron 5 was amplified using $5^{\prime}$-TAATCATATGTGCATGTTTAGGGTGAATGC- $3^{\prime}$ and $5^{\prime}$-TGCTCATATGGCTTGCATGTGAGAGAGCTA-3' ${ }^{\prime}$. Similarly wild-type HRPT2 consisting of the last 294 nucleotides of intron 6, exon 7 (217 bp) and the first 244 nucleotides of intron 7 was

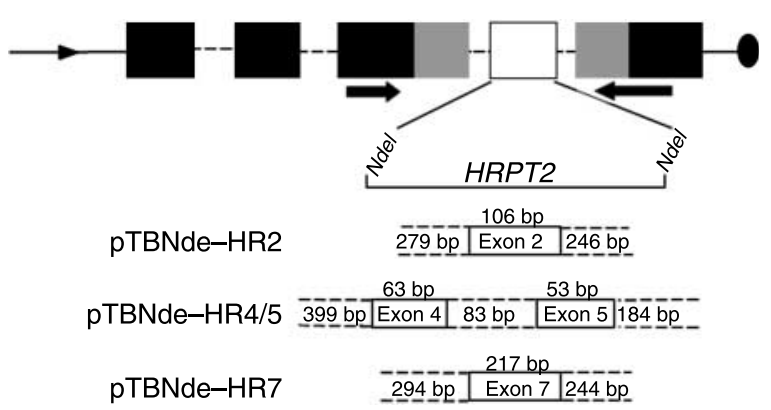

Figure 1 Schematic representation of the $\alpha$-globin (black boxes)/ fibronectin (grey boxes) minigene containing HRPT2 exons $2,4 / 5$ or 7 (intronic sequences shown as dashed lines). The minimal $\alpha$-globin promoter and SV enhancer are marked with an arrow head and the polyadenylation signal with a solid circle. Three different fragments of HRPT2 containing either exon 2 (pTBNde-HR2), exons $4 / 5$ (pTBNde-HR4/5) or exon 7 (pTBNde-HR7) and flanking intronic sequences were cloned into the Ndel site of the hybrid minigene. The position of primers used to analyse transcripts expressed from this minigene are indicated by solid arrows. amplified using $5^{\prime}$-TAATCATATGCCTATATTAATGAGTCCTGCTT- $3^{\prime}$ and $5^{\prime}$-TGCTCATATGTGTGAAGGAGCTTGCATTTT- $3^{\prime}$. The NdeI site within each primer (underlined) was used to clone each PCR product into the unique NdeI site of the mammalian expression vector pTBNde(min) (kind gift of Francisco E Baralle, International Centre for Genetic Engineering and Biotechnology, Trieste, Italy). This vector contains a hybrid minigene composed of the first three introns/exons of the $\alpha$-globulin gene into which a small portion of the fibronectin gene has been inserted (Fig. 1). This hybrid minigene has been used in numerous studies to investigate the splicing of a number of different genes including the neurofibromatosis type 1 gene NF1 and the cystic fibrosis gene CFTR (Pagani et al. 2000, 2003, Baralle et al. 2003). Each HRPT2 minigene construct was verified by sequence analysis (Supamac, The University of Sydney, NSW, Australia).

\section{Site-directed mutagenesis}

HRPT2 mutations previously identified in patients with HPT-JT or parathyroid carcinoma (reviewed in Marsh et al. 2007) that were predicted to disrupt putative ESE sites, two reported splice site mutations (IVS2 $+1 \mathrm{G}>\mathrm{C}$ and IVS6-1delG) as well as four synthetic splicing mutations at donor or acceptor splice sites (IVS1-2A $>$ G, IVS4-2A $>\mathrm{G}$, IVS5 $+1 \mathrm{G}>\mathrm{T}$ and IVS7 $+1 \mathrm{G}>\mathrm{C}$ ) were introduced into the HRPT2 minigene cassettes using the QuickChange II site-directed mutagenesis kit (Stratagene, La Jolla, CA, USA). Synthetic mutants were used as positive controls to test the efficacy of the in vitro splicing assay, a strategy employed in previous studies (Anczukow et al. 2008). Each mutation and the primers used for mutagenesis, as well as the disease associations of these mutations, are listed in Table 1. All mutagenesis was verified by sequence analysis (Supamac).

\section{Cell culture}

Human embryonic kidney (HEK293) and immature osteoblastic (MG63; American Type Culture Collection, Manassas, VA, USA) cells were maintained in DMEM (Gibco, Invitrogen Australia Pty Ltd), supplemented with 10\% FCS (Trace Scientific Ltd, Noble Park, VIC, Australia) and incubated at $37^{\circ} \mathrm{C}$ in a humidified $5 \% \quad \mathrm{CO}_{2}$ atmosphere.

\section{Analysis of minigene expression}

HEK293 cells $\left(2 \times 10^{5} /\right.$ well $)$ were seeded into six-well culture dishes. After $24 \mathrm{~h}$, cells were transfected with $1 \mu \mathrm{g}$ of each wild-type or mutant minigene construct using Fugene 6 according to the manufacturer's instructions (Roche Diagnostics Australia Pty Ltd).

Seventy-two hours after transfection, cytoplasmic RNA was extracted (RNeasy, Qiagen Pty Ltd) and reverse transcribed using SuperScript III First-Strand Synthesis 
Table 1 Primers used for mutagenesis of HRPT2 minigenes

\begin{tabular}{c}
$\begin{array}{c}\text { Mutation } \\
\text { type }\end{array}$ \\
\hline
\end{tabular}

\section{Disease association}

\section{Mutation}

Primers used to generate exon 2 mutants

$$
\text { IVS1-2A }>\mathrm{G}^{\mathrm{a}}
$$

c. $162 \mathrm{C}>\mathrm{G}(\mathrm{Y} 54 \mathrm{X})$

(Howell et al. 2003)

c. 165 delC

(Howell et al. 2003)

c. 165C > A (Y55X)

(Howell et al. 2003)

c. $165 \mathrm{C}>\mathrm{G}(\mathrm{Y} 55 \mathrm{X})$

(Carpten et al. 2002)

c.191T>C (L64P)

(Carpten et al. 2002)

c.195insA

(Cetani et al. 2004)

c.195insT

(Cetani et al. 2004)

c. 226C > T (R76X)

(Shattuck et al. 2003)

IVS2 + 1G $>\mathrm{C}^{\mathrm{b}}$

(Villablanca et al. 2004)

Primers used to generate exon 4 and 5 mutants

IVS4 $-2 \mathrm{~A}>\mathrm{G}^{\mathrm{a}}$

c.356delA

(Carpten et al. 2002)

c.373insA

(Shattuck et al. 2003)

c.406A > T (K136X)

(Carpten et al. 2002)

$\operatorname{IVS} 5+1 \mathrm{G}>\mathrm{T}^{\mathrm{a}}$

\section{Splice}

Site

Nonsense

Frameshift

Nonsense

Nonsense

Missense

Frameshift

Frameshift

Nonsense

Splice

Site

Splice

Site

Frameshift

Frameshift

Nonsense

Splice

Site

Primers used to generate exon 7 mutants

IVS6-1 delG ${ }^{b}$

(Howell et al. 2003)

c.636delT

(Carpten et al. 2002)

c.664C > T (R222X)

(Shattuck et al. 2003)

c.679insAG

(Carpten et al. 2002)

c.679delAG

(Howell et al. 2003)

c.686delGAGT

(Howell et al. 2003)

c.700C $>$ T (R234X)

(Shattuck et al. 2003)

IVS7 + $1 \mathrm{G}>\mathrm{C}^{\mathrm{a}}$

$\begin{array}{ll}\begin{array}{l}\text { Splice } \\ \text { Site } \\ \text { Frameshift }\end{array} & \text { Sp. cancer } \\ \text { Nonsense } & \text { HPT-JT } \\ \text { Frameshift } & \text { HPT-JT } \\ \text { Frameshift } & \text { HPT-JT } \\ \text { Frameshift } & \text { HPT-JT } \\ \text { Nonsense } & \text { Sp. cancer } \\ \text { Splice } & \text { None } \\ \text { Site } & \end{array}$

None

Sp. cancer

Sp. cancer

Sp. cancer

HPT-JT

FIHP

Sp. cancer

Sp. cancer

Sp. cancer

FIHP

None

HPT-JT

FIHP

HPT-JT

None

Sp. cancer

5'-AAGAAATTGCTTTTA_GTCTTTGTCTGAAGC-3'
$5^{\prime}$-GCTTCAGACAAAGAC TAAAAGCAATTTCTT-3'

5'-CCTTAAACAGAGGAG_TTTGTGGATGCTGAG-3'

5'-CTCAGCATCCACAAA_CTCCTCTGTTTAAGG-3'

5'-GAGGTAGATGTGACC TGAGATATTGTCAGCA-3'

5'-TGCTGACAATATCTCAĞGTCACATCTACCTC-3'

5'-CGAGATATTGTCAGCAGAGAGAGAGAGTATGGAGG-3'

5'-CСТCСАTACTCTCTCTCTCTGCTGACAATATCTCG-3'

5'-CGAGATATTGTCAGC AGAGAGAGTATGGAG-3'

5'-CTCCATACTCTCTCT GCTGACAATATCTCG- $3^{\prime}$

5'-ATATTGTCAGCAGAGAGA ATGGAGGACACGAACAAC-3'

5'-GTTGTTCGTGTCCTCCAT_ TCTCTCTGCTGACAATAT-3'

5'-GAGTATGGAGGACATGAACAACTATCTTAC-3'

5'-GTAAGATAGTTGTTCĀTGTCCTCCATACTC-3'

5'-ATCTTACAAAGCACA $\bar{G} G A A A G C T A A T T A A A A T A T T T T A C T C A T-3^{\prime}$

5'-ATGAGTAAAATATTTTAATTAGCTTTCCTGTGCTTTGTAAGAT-3'

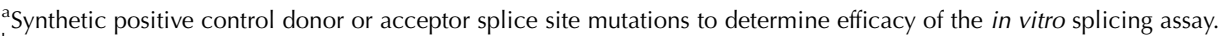

${ }^{b}$ Naturally occurring donor or acceptor splice site mutations.

Disease association is indicated for naturally occurring mutations. Sp. cancer indicates sporadic parathyroid carcinoma.

Mutations are bolded and underlined.
}

SuperMix according to the manufacturer's instructions (Invitrogen Australia Pty Ltd). The minigene $\alpha$-globulin/ fibronectin gene rearrangement within pTBNde (min) does not occur normally, and the use of a reverse primer that spans the $3^{\prime}$ fibronectin/ $\alpha$-globulin exon boundary allows for the analysis of transcripts expressed only from the minigene cassette. cDNA was subjected to PCR (AmpliTaq Gold, Applied Biosystems), using the oligonucleotides 5'-CTCCTAAGCCACTGCCTGCTGGTGA-3' and $5^{\prime}$-GGTCACCAGGAAGTTGGTTAAAATCA- $3^{\prime}$ and the 
following PCR cycles: 35 cycles of $95{ }^{\circ} \mathrm{C}$ for $30 \mathrm{~s} ; 55^{\circ} \mathrm{C}$ for $30 \mathrm{~s}$; and $72{ }^{\circ} \mathrm{C}$ for $30 \mathrm{~s}$. PCR products were separated on $2 \%$ agarose and visualised using ethidium bromide staining. PCR products were either purified immediately after PCR (Wizard PCR Preps DNA Purification System, Promega) or were separated on $2 \%$ agarose and then gel purified (UltraClean GelSpin DNA Purification Kit, MO BIO Laboratories, Inc., Carlsbad, CA, USA) as per the manufacturer's instructions. The sequence of purified PCR products was verified by commercial sequencing (Supamac).

\section{Amplification of $c \mathrm{DNA}$ from parathyroid tissue}

PCR amplification of HRPT2-spanning exons 4-8 was carried out using cDNA generated from tumour tissue of a patient with sporadic parathyroid carcinoma and a previously identified HRPT2 mutation (IVS6-1delG; Howell et al. 2003). Informed consent was obtained according to human ethics protocols. No additional fresh frozen or paraffinembedded tissue was available from this carcinoma. cDNA was subjected to PCR as described above using the primers Ex4F $5^{\prime}$-GCAAGTATAGACAGAAGCGC- $3^{\prime}$ and Ex8R $5^{\prime}$-CACAGGTGCTGCATTTGG-3'. PCR products were purified using the Wizard PCR Preps DNA Purification System (Promega) and cloned into the pGEM ${ }^{\circledR}-\mathrm{T}$ Easy Vector (Promega) as per the manufacturer's instructions. Constructs were verified by sequencing.

\section{Results}

ESE site analysis of 17 endogenously occurring HRPT2 mutations

Seventeen HRPT2 mutations occurring in exons 2, 4, 5 or 7 , which had previously been identified in patients with HPT-JT or parathyroid carcinoma, were analysed by ESEfinder and Rescue-ESE. Out of the 17 HRPT2 mutations analysed, 14 were predicted by ESEfinder to alter ESE sites. Ten out of these mutations resulted in the loss of one or more ESE sites, three mutations induced gain of an ESE site, while one resulted in prediction of a less efficient ESE site, but still above the matrix score threshold level (Fig. 2). Although a number of different ESE sites were predicted by Rescue-ESE to alter as the result of HRPT2 mutation, 11 out of these overlapped with those predicted by ESEFinder (Fig. 2).

Transcripts expressed from wild-type or mutant HRPT2 exon 2 minigene constructs

In HEK293 cells transfected with an empty vector or wildtype HRPT2 exon 2 minigene, a single PCR product of $\sim 300$ or 400 bp respectively was detected. The synthetic IVS1 $-2 \mathrm{~A}>\mathrm{G}$ mutation resulted in transcripts in which exon 2 had been skipped or a portion of exon 2 had been deleted (Fig. 3A). The donor splice site mutation IVS2 $+1 \mathrm{G}>\mathrm{C}$ that
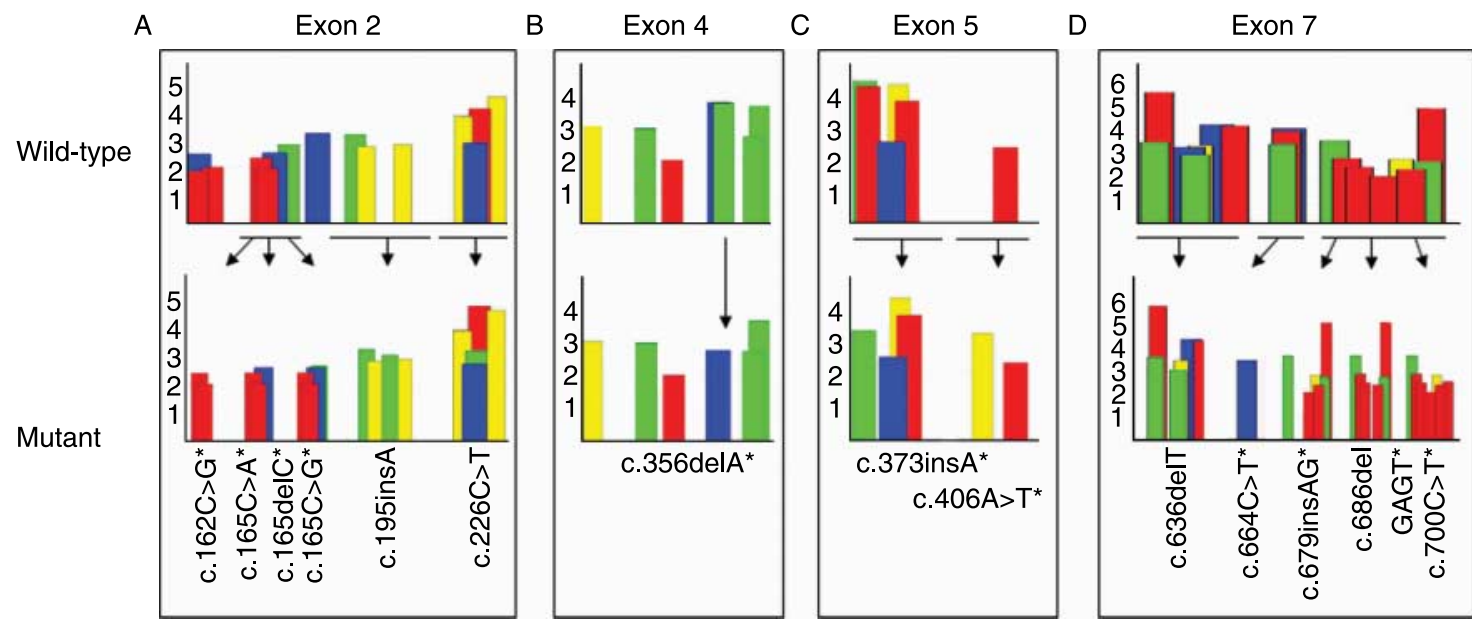

Figure 2 Out of the 17 reported HRPT2 mutations, 14 were predicted by ESEFinder to disrupt ESE sites of one or more of four different SR proteins (SF2/ASF (red), SC35 (blue), SRp40 (green), SRp55 (yellow)). Predicted ESE sites within wild-type HRPT2 exons 2 (A), 4 (B), 5 (C) and 7 (D) are shown in the top panels. Coloured bars represent individual ESE sites with the matrix score (higher score represents a stronger prediction) plotted on the $y$-axis and the position of the ESE within each HRPT2 exon represented on the $x$-axis. Matrix score changes induced by each mutation are represented in the lower panels. If matrix scores for a particular SR protein fell below threshold levels as predicted by ESEFinder (SF2/ASF $=1 \cdot 956, \mathrm{SC} 35=2 \cdot 383, \mathrm{SRp} 40=2 \cdot 67, \mathrm{SRp} 55=2 \cdot 676$ ), the coloured bar representing an ESE site was lost. In the case of c.165C > G, the matrix score for SRp40 was reduced but remained above threshold level. Mutations marked with an * were predicted by both ESEFinder and Rescue-ESE to disrupt ESE binding sites. 
A

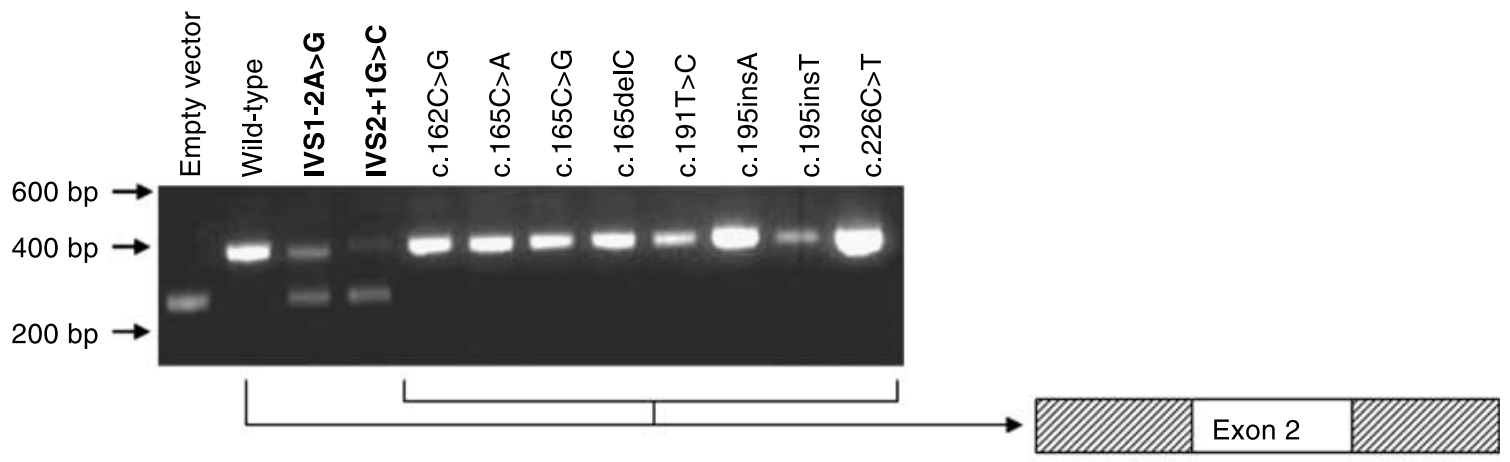

B

IVS2+1G>C
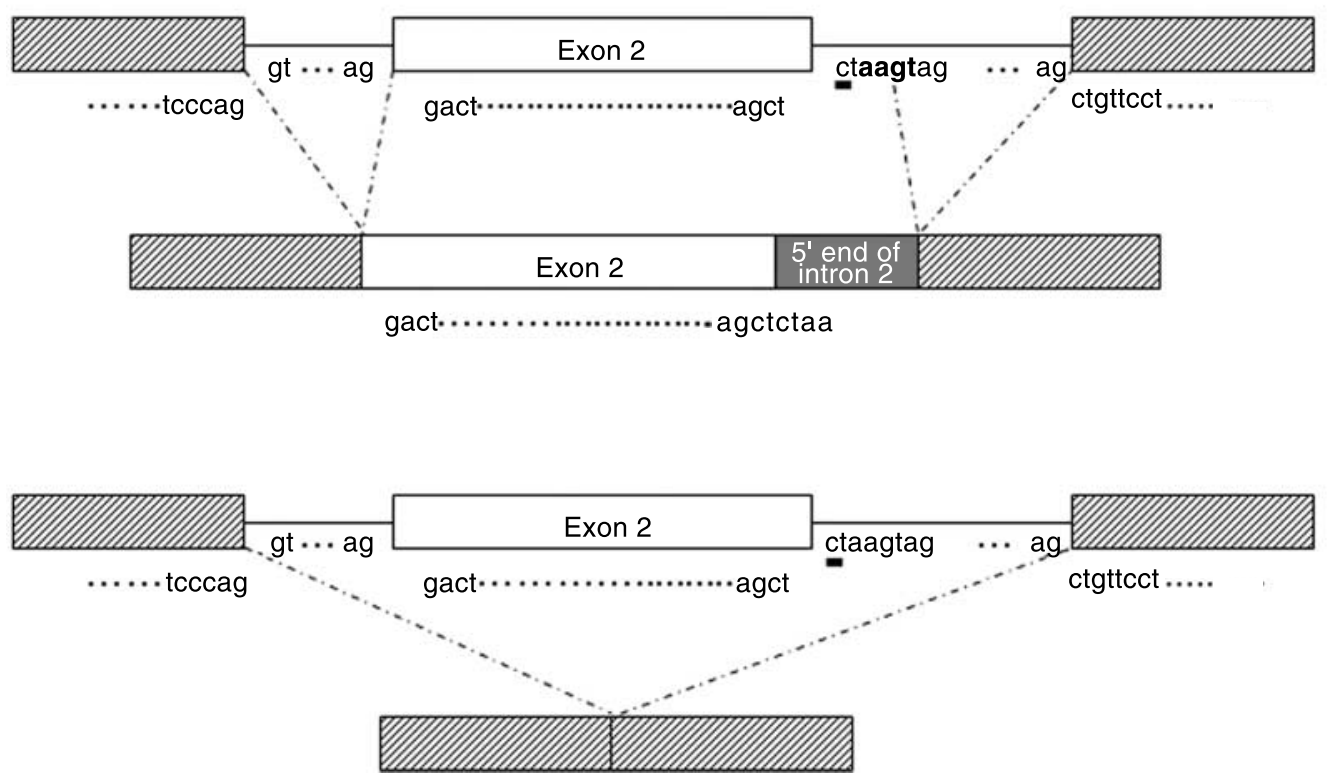

Figure 3 In vitro splicing analyses of wild-type and mutant HRPT2 exon 2 and flanking sequence. (A) PCR products expressed from the wild-type or mutated HRPT2 minigene. Minigenes containing each of the HRPT2 exon 2 mutations were spliced identically to wild-type. Canonical splice site mutations (in bold) led to aberrant splicing products. (B) Schematic representation of the splicing outcomes for the splice site mutation IVS2 $+1 \mathrm{G}>\mathrm{C}$. The IVS2 $+1 \mathrm{G}>\mathrm{C}$ mutation is underlined and newly generated splice signals are shown in bold. Hatched boxes represent fibronectin exons belonging to the pTBNde(min) mammalian expression vector.

has been reported in a family with FIHP (Villablanca et al. 2004) caused either exon 2 skipping resulting in premature truncation of parafibromin at residue 73 , or retention of four nucleotides at the $5^{\prime}$ end of intron 2 by way of use of the cryptic donor-splicing signal AAGT (Fig. 3B). This sequence deviates from classical consensus motifs for donor splice sites (Cartegni et al. 2002). The aberrant splice product generated by retention of intronic sequence is predicted to lead to premature truncation of parafibromin at residue 82 following two non-parafibromin amino acids.

By contrast, cells transfected with the HRPT2 exon 2 minigene harbouring exonic mutations generated a single PCR product similar in size to the wild-type HRPT2 product, indicating that none of these changes altered exon 2 splicing (Fig. 3A). Direct sequencing of all transcripts verified these observations.

Nine exonic mutations in exon 4/5 or 7 of HRPT2 do not disrupt splicing

In HEK293 cells transfected with the empty vector, wildtype, or mutated HRPT2 exon $4 / 5$, a single PCR product was generated (Fig. 4). The two synthetic mutations at donor or acceptor splice sites used as positive controls to test the efficacy of the in vitro splicing assay led to transcripts in which exon 5 had been skipped (IVS5 $+1 \mathrm{G}>\mathrm{T}$ ), or a portion of 


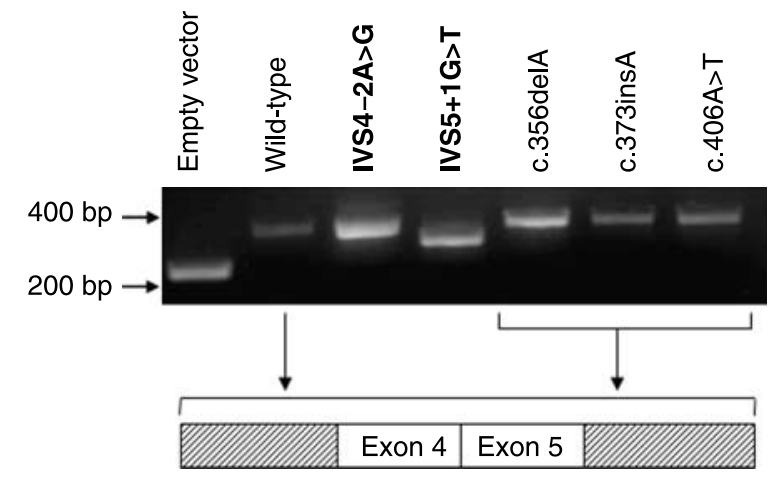

Figure 4 In vitro splicing analyses of wild-type and mutant HRPT2 exons $4 / 5$ and flanking sequence. PCR products expressed from the wild-type or mutated exon 4/5 HRPT2 minigene. Canonical splice site mutations (in bold) led to aberrant splicing products. Schematic shows that minigenes containing each of the HRPT2 exon 4/5 mutations were spliced identically to wild-type. Hatched boxes represent fibronectin exons belonging to the pTBNde(min) mammalian expression vector.

exon 5 had been deleted (IVS4-2A $>$ G). The three exonic HRPT2 exon 4 or 5 mutations did not alter the splicing of these exons and their flanking intronic sequences (Fig. 4).

Similarly, to assess HRPT2 exon 7 splicing, two donor or acceptor splice site mutations were analysed (Fig. 5). The IVS7 $+1 \mathrm{G}>\mathrm{C}$ synthetic mutation resulted in transcripts with either loss of some exon 7 sequence or exon 7 skipping. The IVS6-1delG mutant, reported in a case of sporadic parathyroid carcinoma (Howell et al. 2003), led to two aberrant transcripts. The first retained the last 40 nucleotides of intron 6 as a direct result of use of the cryptic acceptorsplicing signal AGGA (Fig. 5B). Translation of this mutant transcript suggests that parafibromin would be prematurely truncated at amino acid 188 after a string of 16 nonparafibromin amino acids. The second aberrant transcript was missing the first $G$ of exon 7 as a direct result of loss of the $G$ at position -1 of IVS6 constituting part of the canonical acceptor splice site AGGT. This loss resulted in use of the A at position -2 of IVS6 and the first three nucleotides of exon 7 (GTC) as the new splice recognition signal AGTC. This sequence deviates from classical consensus motifs for acceptor splice sites (Cartegni et al. 2002). Translation of this mutant transcript suggests that parafibromin would be prematurely truncated at residue 201 after a string of 30 non-parafibromin amino acids. By contrast, six HRPT2 mutations in exon 7 did not alter splicing (Fig. 5A). Direct sequencing confirmed these results.

\section{HRPT2 IVS6-1delG splicing in parathyroid carcinoma}

Parathyroid tumour tissue was available from a patient with sporadic parathyroid carcinoma and the somatic HRPT2 mutation IVS6-1delG. As observed in the in vitro splicing assay, the cryptic splice signal AGGA in intron 6 was used resulting in retention of the last 40 nucleotides of intron 6 .
Wild-type transcript was also observed, most likely transcribed from the wild-type allele we had previously shown was retained in this tumour (Howell et al. 2003; Fig. 6). The other transcript observed in the in vitro splicing assay was not seen in tumour tissue. We believe the likely explanation is that wild-type HRPT2 transcript expressed from the retained allele was in greater abundance than this alternative transcript in tumour tissue. Sequencing of a large number of clones would likely have revealed this additional transcript in tumour tissue.

\section{Discussion}

We have developed an in vitro assay to determine the effect on splicing of HRPT2 mutations occurring at canonical donor/acceptor splice sites, as well as those predicted to disrupt putative ESE sites. Mutations occurring at splice sites led to aberrant splicing including exon skipping or retention of intronic sequence; however, only wild-type splicing patterns were observed for all exonic HRPT2 mutations predicted to disrupt ESE sites.

Four point mutations resulting in nucleotide substitutions at canonical GT splice donor or AG splice acceptor sites have been reported to date in HRPT2 (Howell et al. 2003, Villablanca et al. 2004, Bradley et al. 2005, Moon et al. 2005). While the splicing effects of two of these mutations have been previously reported (Bradley et al. 2005, Moon et al. 2005, Table 2), we have used our splicing assay to determine the effects of the remaining two. IVS2 $+1 \mathrm{G}>\mathrm{C}$ identified in members of an FIHP family (Villablanca et al. 2004) led to exon 2 skipping, as well as retention of four nucleotides at the $5^{\prime}$ end of intron 2 through use of the cryptic donor-splicing signal AAGT. While this signal contains the nearly invariant GT, the exonic nucleotides making up this signal do not constitute previously described classical donor splice signal consensus motifs (Cartegni et al. 2002).

The IVS6-1delG mutation previously reported in a sporadic parathyroid carcinoma (Howell et al. 2003) was analysed in both the splicing assay and in tumour tissue from an affected patient. This mutant resulted in retention of the last 40 nucleotides of intron 6 through use of the cryptic acceptor splice signal AGGA. A second transcript was generated by use of the cryptic acceptor splice signal AGTC as the consequence of the loss of a G. While this signal contains the nearly invariant $A G$, the exonic nucleotides making up this sequence do not constitute previously described classical acceptor splice signal consensus motifs (Cartegni et al. 2002). Analysis of HRPT2 transcripts from tumour tissue from the patient with the sporadic parathyroid carcinoma was consistent with results from the splicing assay.

Previous studies have also identified discrepancies between predictive and functional analyses of ESE sites. Anczuków et al. (2008) used an in vitro splicing assay to determine whether 108 variants of unknown significance in BRCA1, 
A

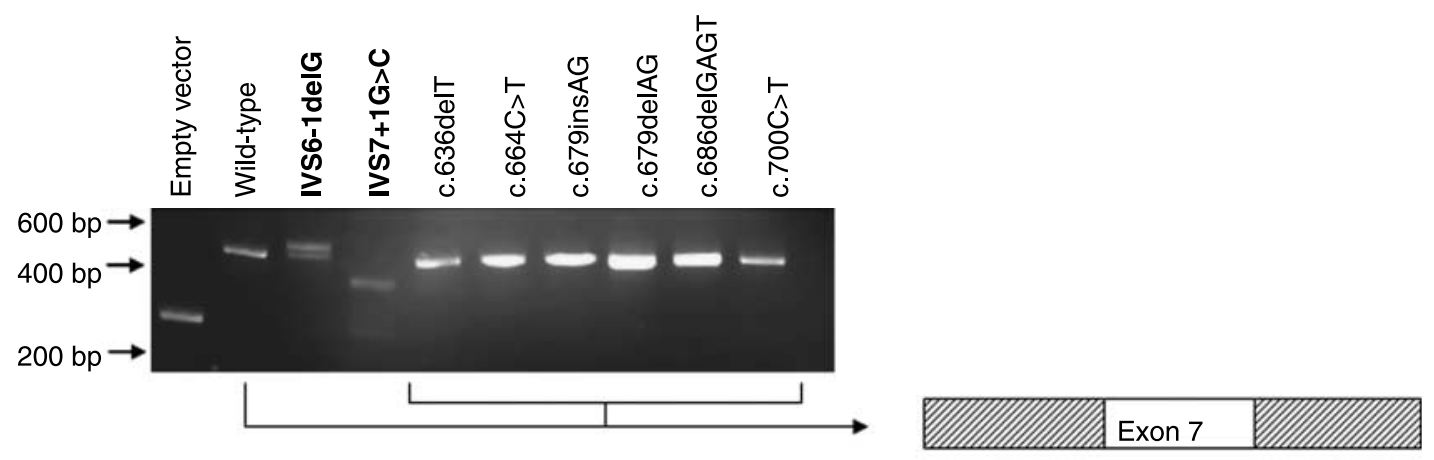

B

gaat..........tttagtct...........aaag

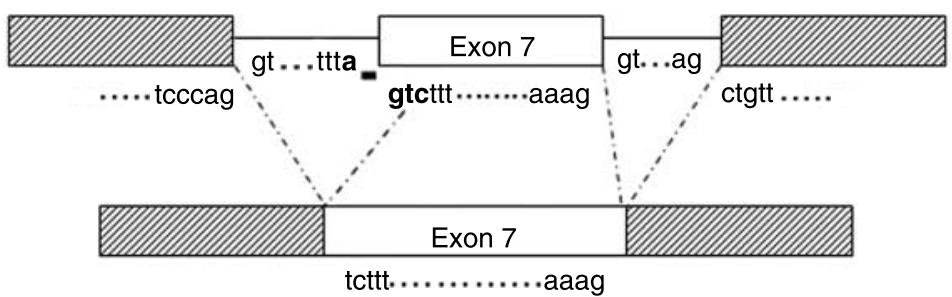

Figure 5 In vitro splicing analyses of wild-type and mutant HRPT2 exon 7 and flanking sequence. (A) PCR products expressed from the wild-type or mutated HRPT2 minigene. Minigenes containing each of the HRPT2 exon 7 mutations were spliced identically to wild-type. Canonical splice site mutations (in bold) led to aberrant splicing products. (B) Schematic representation of the splicing outcomes for the IVS6 - 1delG mutation. The IVS6 - 1delG mutation is underlined and newly generated splice signals are shown in bold. Hatched boxes represent fibronectin exons belonging to the pTBNde(min) mammalian expression vector.

including missense mutations, silent variants and small deletions and insertions might cause aberrant splicing. Approximately $70 \%$ of mutations were predicted to either abolish or decrease the threshold score of a putative ESE site. While they were able to identify previously reported wildtype alternative transcripts, only one mutant was found to have an effect on splicing. This was not confirmed in a human lymphoblastoid cell line from a patient carrying this mutation. While the possibility that splicing may have been tissue specific in this case could not be excluded, this mutation was later shown not to segregate with all cases of early bilateral breast cancer patients in this family (Anczuków et al. 2008). Additionally, Lastella et al. (2004) used an in vitro splicing assay to analyse mutants in exon 12 of hMLH1 predicted to disrupt ESE sites, and found that only 4 out of 16 led to aberrant splicing of exon 12 .
SR proteins are known to be differentially expressed in different cell types and tissues. For example, expression of SF2/ASF and its agonist hnRNP varies greatly in rat tissues including heart, ovaries, liver and pancreas (Hanamura et al. 1998). A study of SR proteins in calf tissues including kidney, skeletal muscle, liver, heart, lung, thymus and brain also shows considerable variability of expression (Zahler et al. 1993). We are unable to exclude the likelihood that we did not see aberrant splicing from mutations at putative ESE sites in our HEK293 cell model due to lack of tissue-specific expression of elements of the necessary splicing machinery. However, this is a less likely explanation, given that identical results were seen for a number of mutations analysed in the osteosarcoma cell line MG63 transfected with our splice assay constructs (data not shown). 


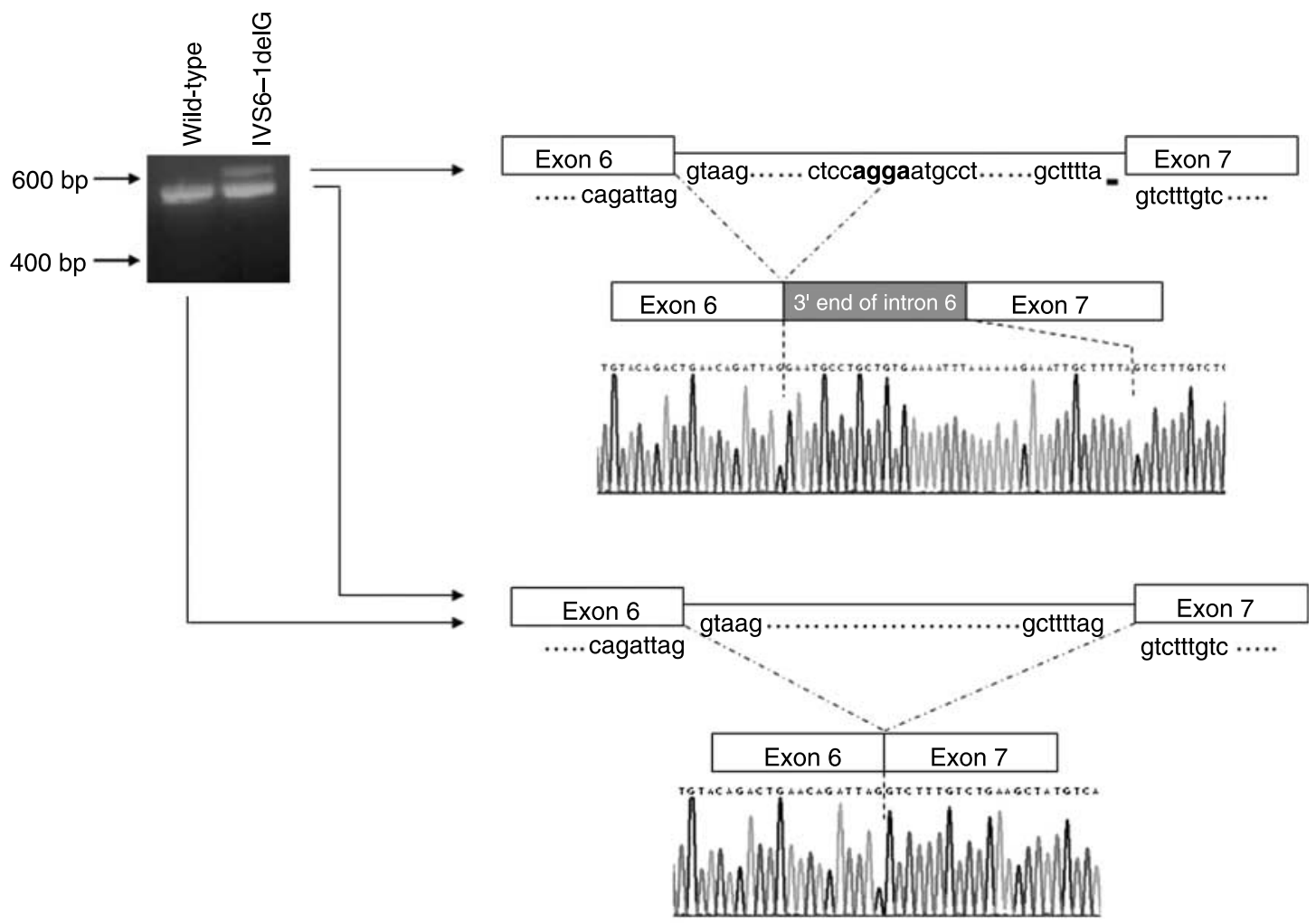

Figure 6 Splicing outcomes obtained from HEK293 cells in which wild-type HRPT2 is expressed or cDNA obtained from a parathyroid carcinoma harbouring IVS6-1delG. The IVS6-1delG mutation is underlined and newly generated splice signals are shown in bold.

This study has elucidated aberrant transcripts and the mechanisms by which they have been generated for canonical donor/acceptor splice site mutations in HRPT2. It is unlikely that additional splicing aberrations caused by disruption of ESE sites play a role in the pathogenicity of exonic HRPT2 mutations. While predictive programs may be useful in giving a preliminary indication of the effect of sequence variants on splicing, functional assays are required to determine the true effects, if any, on splicing.

Table 2 Splicing mutants reported in Hyperparathyroidism-Jaw Tumour (HPT-JT), Familial Isolated Hyperparathyroidism (FIHP) or sporadic carcinoma

\begin{tabular}{|c|c|c|c|c|c|}
\hline & Effect on transcript & $\begin{array}{l}\text { Cryptic donor } \\
\text { splice site used }\end{array}$ & $\begin{array}{l}\text { Cryptic acceptor } \\
\text { splice site used }\end{array}$ & $\begin{array}{l}\text { Predicted effect on } \\
\text { parafibromin }\end{array}$ & Phenotype \\
\hline \multicolumn{6}{|l|}{ Mutation } \\
\hline $\mathrm{IVS} 1+1 \mathrm{G}>\mathrm{A}$ & $\begin{array}{l}\text { Deletion of } 30 \text { nts in exon } \\
1(+102 \text { to }+131)\end{array}$ & 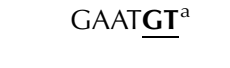 & - & $\begin{array}{l}\text { In frame loss of } \\
\text { residues } 35-44\end{array}$ & $\begin{array}{l}\text { FIHP; } \\
\quad \text { Bradley et al. (2005) }\end{array}$ \\
\hline \multirow[t]{2}{*}{ IVS2-1G $>$ A } & Exon 3 skipping & - & - & Truncation at residue 85 & HPT-JT; \\
\hline & $\begin{array}{l}\text { Deletion of first } 23 \text { nts of } \\
\text { exon } 3\end{array}$ & & $\underline{\mathrm{AGAA}^{\mathrm{a}}}$ & Truncation at residue 82 & Moon et al. (2005) \\
\hline \multirow[t]{2}{*}{ IVS2 $+1 G>C^{b}$} & Exon 2 skipping & - & - & Truncation at residue 73 & FIHP; Villablanca \\
\hline & $\begin{array}{l}\text { Retention of } 4 \text { nts at } 5 \text { ' } \\
\text { end of IVS2 }\end{array}$ & $\mathrm{AAC}^{\mathrm{G}}$ & & Truncation at residue 82 & et al. (2004) \\
\hline \multirow[t]{2}{*}{ IVS6-1 delG } & Retention of 40 nts at $5^{\prime}$ & - & AGGA & Truncation at residue 188 & \multirow{2}{*}{$\begin{array}{l}\text { Sporadic parathyroid } \\
\text { carcinoma; Howell } \\
\text { et al. (2003) }\end{array}$} \\
\hline & c.513delG & & AGTC $^{\mathrm{a}}$ & Truncation at residue 201 & \\
\hline
\end{tabular}

nts, nucleotides.

${ }^{a}$ Cryptic donor or acceptor splice sites used that are comprised of non-classical splicing consensus motifs (Cartegni et al. 2002).

${ }^{b}$ Effect of mutation reported in this study in an in vitro splicing assay.

${ }^{\mathrm{C}}$ Effect of mutation reported in this study both in vitro and in vivo.

Splicing motifs (Cartegni et al. 2002) are indicated with the nearly invariant GT and AG dinucleotides either at the $5^{\prime}$ or $3^{\prime}$ end of the intron bolded and underlined. 


\section{Declaration of interest}

There is no conflict of interest that could be perceived as prejudicing the impartiality of the research reported.

\section{Funding}

This work was supported by the Australian National Health and Medical Research Council (302161) and the Cancer Institute NSW (Fellowship to $\mathrm{D} J \mathrm{M})$.

\section{Author contribution statement}

Dr Hahn supervised Ms McDonnell to conduct this project and was involved in all aspects of experimental design and data analysis. He co-wrote the paper with Dr Marsh.

Ms McDonnell functioned as a research assistant on this project and conducted much of the cloning, transfections and sequencing described under the supervision of Drs Hahn and Marsh.

Dr Marsh was responsible for conceiving this project and obtaining grant funding to conduct it. She was responsible for supervision of research staff carrying out this project. She was involved in all aspects of experimental design and data analysis and co-wrote the paper with Dr Hahn.

\section{Acknowledgements}

Dr Viive Howell is thanked for helpful discussions during preparation of this manuscript.

\section{References}

Anczukow O, Buisson M, Salles MJ, Triboulet S, Longy M, Lidereau R, Sinilnikova OM \& Mazoyer S 2008 Unclassified variants identified in BRCA1 exon 11: consequences on splicing. Genes, Chromosomes and Cancer 47 418-426.

Aretz S, Uhlhaas S, Sun Y, Pagenstecher C, Mangold E, Caspari R, Moslein G, Schulmann K, Propping P \& Friedl W 2004 Familial adenomatous polyposis: aberrant splicing due to missense or silent mutations in the APC gene. Human Mutation 24 370-380.

Baralle M, Baralle D, De Conti L, Mattocks C, Whittaker J, Knezevich A, Ffrench-Constant C \& Baralle FE 2003 Identification of a mutation that perturbs NF1 agene splicing using genomic DNA samples and a minigene assay. Journal of Medical Genetics 40 220-222.

Blencowe BJ 2006 Alternative splicing: new insights from global analyses. Cell $12637-47$

Bradley KJ, Cavaco BM, Bowl MR, Harding B, Young A \& Thakker RV 2005 Utilisation of a cryptic non-canonical donor splice site of the gene encoding PARAFIBROMIN is associated with familial isolated primary hyperparathyroidism. Journal of Medical Genetics 42 e51.

Bradley KJ, Cavaco BM, Bowl MR, Harding B, Cranston T, Fratter C, Besser GM, Conceicao Pereira M, Davie MW, Dudley N et al. 2006 Parafibromin mutations in hereditary hyperparathyroidism syndromes and parathyroid tumours. Clinical Endocrinology 64 299-306.

Carpten JD, Robbins CM, Villablanca A, Forsberg L, Presciuttini S, BaileyWIlson J, Simonds WF, Gillanders EM, Kennedy AM, Chen JD et al. 2002 HRPT2, encoding parafibromin, is mutated in hyperparathyroidism-jaw tumor syndrome. Nature Genetics 32 676-680.

Cartegni L, Chew SL \& Krainer AR 2002 Listening to silence and understanding nonsense: exonic mutations that affect splicing. Nature Reviews. Genetics 3 285-298.
Cartegni L, Wang J, Zhu Z, Zhang MQ \& Krainer AR 2003 ESEfinder: a web resource to identify exonic splicing enhancers. Nucleic Acids Research 31 3568-3571.

Cetani F, Pardi E, Borsari S, Viacava P, Dipollina G, Cianferotti L, Ambrogini E, Gazzerro E, Colussi G, Berti P et al. 2004 Genetic analyses of the HRPT2 gene in primary hyperparathyroidism: germline and somatic mutations in familial and sporadic parathyroid tumors. Journal of Clinical Endocrinology and Metabolism 89 5583-5591.

Cetani F, Pardi E, Ambrogini E, Viacava P, Borsari S, Lemmi M, Cianferotti L, Miccoli P, Pinchera A, Arnold A et al. 2007 Different somatic alterations of the HRPT2 gene in a patient with recurrent sporadic primary hyperparathyroidism carrying an HRPT2 germline mutation. Endocrine-Related Cancer 14 493-499.

Colapietro P, Gervasini C, Natacci F, Rossi L, Riva P \& Larizza L 2003 NF1 exon 7 skipping and sequence alterations in exonic splice enhancers (ESEs) in a neurofibromatosis 1 patient. Human Genetics 113 551-554.

Fackenthal JD, Cartegni L, Krainer AR \& Olopade OI 2002 BRCA2 $\mathrm{T} 2722 \mathrm{R}$ is a deleterious allele that causes exon skipping. American Journal of Human Genetics 71 625-631.

Fairbrother WG, Yeh RF, Sharp PA \& Burge CB 2002 Predictive identification of exonic splicing enhancers in human genes. Science 297 1007-1013.

Hanamura A, Caceres JF, Mayeda A, Franza BR Jr \& Krainer AR 1998 Regulated tissue-specific expression of antagonistic pre-mRNA splicing factors. RNA 4 430-444.

Howell VM, Haven CJ, Kahnoski K, Khoo SK, Petillo D, Chen J, Fleuren GJ, Robinson BG, Delbridge LW, Philips J et al. 2003 HRPT2 mutations are associated with malignancy in sporadic parathyroid tumours. Journal of Medical Genetics 40 657-663.

Kelly TG, Shattuck TM, Reyes-Mugica M, Stewart AF, Simonds WF, Udelsman R, Arnold A \& Carpenter TO 2006 Surveillance for early detection of aggressive parathyroid disease: carcinoma and atypical adenoma in familial isolated hyperparathyroidism associated with a germline HRPT2 mutation. Journal of Bone and Mineral Research 21 1666-1671.

Lastella P, Resta N, Miccolis I, Quagliarella A, Guanti G \& Stella A 2004 Site directed mutagenesis of hMLH1 exonic splicing enhancers does not correlate with splicing disruption. Journal of Medical Genetics 41 e72.

Marsh DJ, Hahn MA, Howell VM \& Gill AJ 2007 Molecular diagnosis of primary hyperparathyroidism in familial cancer syndromes. Expert Opinion on Medical Diagnostics $1377-392$.

Mazoyer S, Puget N, Perrin-Vidoz L, Lynch HT, Serova-Sinilnikova OM \& Lenoir GM 1998 A BRCA1 nonsense mutation causes exon skipping. American Journal of Human Genetics 62 713-715.

Montera M, Piaggio F, Marchese C, Gismondi V, Stella A, Resta N, Varesco L, Guanti G \& Mareni C 2001 A silent mutation in exon 14 of the APC gene is associated with exon skipping in a FAP family. Journal of Medical Genetics 38 863-867.

Moon SD, Park JH, Kim EM, Kim JH, Han JH, Yoo SJ, Yoon KH, Kang MI, Lee KW, Son HY et al. 2005 A novel IVS2-1G > A mutation causes aberrant splicing of the HRPT2 gene in a family with hyperparathyroidism-jaw tumor syndrome. Journal of Clinical Endocrinology and Metabolism 90 878-883.

Nystrom-Lahti M, Holmberg M, Fidalgo P, Salovaara R, de la Chapelle A, Jiricny J \& Peltomaki P 1999 Missense and nonsense mutations in codon 659 of MLH1 cause aberrant splicing of messenger RNA in HNPCC kindreds. Genes, Chromosomes and Cancer 26 372-375.

Pagani F, Buratti E, Stuani C, Romano M, Zuccato E, Niksic M, Giglio L, Faraguna D \& Baralle FE 2000 Splicing factors induce cystic fibrosis transmembrane regulator exon 9 skipping through a nonevolutionary conserved intronic element. Journal of Biological Chemistry 275 21041-21047.

Pagani F, Stuani C, Tzetis M, Kanavakis E, Efthymiadou A, Doudounakis S, Casals T \& Baralle FE 2003 New type of disease causing mutations: the example of the composite exonic regulatory elements of splicing in CFTR exon 12. Human Molecular Genetics 12 1111-1120. 
Rozenblatt-Rozen O, Hughes CM, Nannepaga SJ, Shanmugam KS, Copeland TD, Guszczynski T, Resau JH \& Meyerson M 2005 The parafibromin tumour suppressor protein is part of a human Paf1 complex. Molecular and Cellular Biology 25 612-620.

Shattuck TM, Valimaki S, Obara T, Gaz RD, Clark OH, Shoback D, Wierman ME, Tojo K, Robbins CM, Carpten JD et al. 2003 Somatic and germ-line mutations of the HRPT2 gene in sporadic parathyroid carcinoma. New England Journal of Medicine 349 1722-1729.

Simonds WF, Robbins CM, Agarwal SK, Hendy GN, Carpten JD \& Marx SJ 2004 Familial isolated hyperparathyroidism is rarely caused by germline mutation in HRPT2, the gene for the hyperparathyroidismjaw tumor syndrome. Journal of Clinical Endocrinology and Metabolism 89 96-102.

Villablanca A, Calender A, Forsberg L, Hoog A, Cheng J-D, Petillo D, Bauters C, Kahnoski K, Ebeling T, Salmela P et al. 2004 Germline and de novo mutations in the HRPT2 tumour suppressor gene in familial isolated hyperparathyroidism (FIHP). Journal of Medical Genetics 41 e32.
Yart A, Gstaiger M, Wirbelauer C, Pecnik M, Anastasiou D, Hess D \& Krek W 2005 The HRPT2 tumor suppressor gene product parafibromin associates with human PAF1 and RNA polymerase II. Molecular and Cellular Biology 25 5052-5060.

Zahler AM, Neugebauer KM, Lane WS \& Roth MB 1993 Distinct functions of SR proteins in alternative pre-mRNA splicing. Science 260 219-222.

Zhao J, Yart A, Frigerio S, Perren A, Schraml P, Weisstanner C, Stallmach T, Krek W \& Moch H 2007 Sporadic human renal tumors display frequent allelic imbalances and novel mutations of the HRPT2 gene. Oncogene 26 3440-3449.

Received in final form 2 March 2009

Accepted 30 March 2009

Made available online as an Accepted Preprint 30 March 2009 